\title{
Effects of In-Situ Proton-Irradiation and Thermal-Pulse on the High-Cycle Fatigue Properties of Low Carbon 316 Stainless Steels
}

\author{
H. Mizubayashi, K. Tateishi, H. Tanimoto and K. Nakata* \\ Institute of Materials Science, University of Tsukuba, Tsukuba 305, Japan \\ ** Hitachi Research Laboratory, Hitachi Ltd., Hitachi 317, Japan
}

\begin{abstract}
For the modified 316L stainless steel in which the dislocation interaction governs the fatigue hardening process, the high-cycle fatigue tests were carried out between 300 and $403 \mathrm{~K}$. The in situ irradiation tests and the in situ thermal-pulse tests indicate that dislocation rearrangements due to thermal-pulse give rise to an increase in the areal density of persistent slip bands (PSBs), resulting in elongation of the fatigue life $N_{\mathrm{f}}$, and an introduction of obstacles to dislocation motions, irradiation induced lattice defects or the fatigue induced precipitates, brings about a decrease in the areal density of PSBs, giving shortening of $N_{\mathrm{f}}$.
\end{abstract}

\section{INTRODUCTION}

The first wall of a fusion reactor is planned to be subjected to thermal stresses and $14 \mathrm{MeV}$ neutron irradiation simultaneously. For the dynamic mechanical properties such as the fatigue property, understanding of effects of in situ radiation damage and in situ thermal pulse is important. However, knowledge on these effects on the fatigue properties is very limited (e.g., [1-3]). One of reasons is a limited radiation damage rate which is not enough to modify considerably the low cycle fatigue property. However, the high cycle fatigue property is expected to be modified under the available radiation damage rate of $10^{-6}-10^{-7} \mathrm{dpa} / \mathrm{s}$, where the effects of in situ radiation damage may more clearly be investigated. Understanding of the high cycle fatigue property itself may also be important, because the most of the structural reactor materials is expected to be subjected to the high cycle fatigue stresses during the reactor operation. The preliminary work on the Ti-modified AISI 316L stainless steel (see [4] and 316(ST-1) below) indicates that the effect of radiation damage on the fatigue life $N_{\mathrm{f}}$ in the $\varepsilon_{\mathrm{t}}$-controlled tests at $333 \mathrm{~K}$, here elongation in $N_{\mathrm{f}}$, is much larger under irradiation than after irradiation, where $\varepsilon_{\mathrm{t}}$ is the total strain amplitude. The further study on the various modified-316L stainless steels $[5,6]$ shows that the fatigue hardening mainly governs $N_{\mathrm{f}}$ of the solution treated specimens and in situ radiation damage or thermal pulse modifies the fatigue hardening process. That is, the elongation in $N_{\mathrm{f}}$ observed for $316(\mathrm{ST}-1)$ is mainly due to enhancement of the fatigue induced precipitation under irradiation. After these results, we started the $\varepsilon_{\mathrm{p}}$-controlled tests on the $316 \mathrm{~L}$ stainless steels with the decreased carbon contents, where $\varepsilon_{\mathrm{p}}$ is the constituent plastic strain amplitude in $\varepsilon_{\mathrm{t}}$ and the dislocation behavior is expected to be pursued more quantitatively in the $\varepsilon_{\mathrm{p}}$-controlled tests than in the $\varepsilon_{\mathrm{t}}$-controlled tests. The preliminary tests at $333 \mathrm{~K}$ on 316SI (see Table 1) [6] indicate that $N_{\mathrm{f}}$ shows elongation for the thermal-pulse $(\Delta T)$ tests (the TP-tests) with $\Delta T$ below $10 \mathrm{~K}$ (see Fig. 1) and shortening under in situ radiation damage (see Fig.2), where the effect of in situ radiation damage is found after the subtraction of the results of the TP-tests from the results of the pulse $20 \mathrm{MeV}$-proton irradiation tests (the pulse-PI-tests). To pursue the further insight into the fatigue process in $316 \mathrm{SI}$, we carried out the TP-tests at $300 \mathrm{~K}$ with the increased $\Delta T$ of about $100 \mathrm{~K}$ and the continuous $20 \mathrm{MeV}$-proton irradiation tests (the PI-tests) at $403 \mathrm{~K}$, because the effects of in situ radiation damage or thermal pulse on the fatigue hardening at $403 \mathrm{~K}$ have been compiled in [6] and the specimen temperature attained during thermal-pulses is about $400 \mathrm{~K}$. Further for the no-loading tests (the NL-tests) without thermal-pulse nor proton irradiation, the fatigue properties at $300 \mathrm{~K}$ are practically the same to those at $333 \mathrm{~K}$ which have also been compiled in [6]. 


\section{EXPERIMENTAL}

Specimens were cut from the rolled sheets of 316 SI with the chemical composition shown in Table 1 . After mechanical polishing, specimens were annealed at $1370 \mathrm{~K}$ for $3.6 \mathrm{ks}$ in a vacuum of $2 \times 10^{-4} \mathrm{~Pa}$ and then quenched into water. As quenched specimens were electroytically polished, in order to remove the surface layer of about $0.05 \mathrm{~mm}$ and to smooth out the surfaces, and then annealed again at $573 \mathrm{~K}$ for $36 \mathrm{ks}$ in a vacuum of $2 \times 10^{-4} \mathrm{~Pa}$ to degas hydrogen picked up during the electrolytical polishing. The grain size was typically $0.05 \mathrm{~mm}$. The fatigue tests were carried out using the flexural vibrations of a U-shaped reed specimen, where the middle of the U-shape forms a composite reed with thickness of $0.12 \mathrm{~mm}$ and a gage length of $16 \mathrm{~mm}$ and two open ends of the U-shape are thick for clamping. Excitation of the flexural vibrations was made electromagnetically and the fatigue tests were conducted in the atmosphere of $10^{2} \mathrm{~Pa}$ He to suppress a heat-up of a specimen (see $[4,6]$ for details). Period $P$ of the resonant flexural vibrations of a specimen in the elastic range will be referred to as $P_{0}$ below, where $1 / P_{0}$ here is about $200 \mathrm{~Hz}$. The fatigue tests were started by an increase in $\varepsilon_{\mathrm{t}}$ beyond micro yielding. For the $\varepsilon_{\mathrm{t}}$-controlled tests (see Fig.1 in [5]), $P$ shows a strong increase during several $10^{3}$ cycles after the increase in $\varepsilon_{\mathrm{t}}$, and then turns to decrease due to the fatigue hardening, where $\varepsilon_{p}$ is proportional to $\left(P-P_{0}\right) / P_{0}$. With increasing fatigue cycles, the fatigue hardening tends towards saturation and at the fatigue cycles of about $0.9 N_{\mathrm{f}} P$ turns to increase reflecting a decrease in the cross-sectional area of the specimen due to the start of crack propagation. That is, the most of $N_{\mathrm{f}}$ is governed by the dislocation behaviors. In the present $\varepsilon_{\mathrm{p}}$-controlled tests, $P$ was held at a given value $P_{\mathrm{h}}$ by adjusting $\varepsilon_{\mathrm{t}}$ during the fatigue hardening and then, after the saturation of the fatigue hardening, $\varepsilon_{\mathrm{t}}$ was kept at an attained $\varepsilon_{\mathrm{t}}$. For the TP-tests, a thermal pulse $\Delta T$ for $10 \mathrm{~s}$ was given every $30 \mathrm{~s}$ using halogen lamp light, where the specimen temperature rises to $90 \%$ of the ultimate $\Delta T$ in a few seconds. For the PI-tests or the pulse-PI-tests, irradiation was made using $20 \mathrm{MeV}$ protons of $0.02-0.03 \mathrm{~A} / \mathrm{m}^{2}$ from the tandem accelerator at University of Tsukuba, where the radiation damage rate estimated is about $1 \times 10^{-7} \mathrm{dpa} / \mathrm{s}$ for $0.025 \mathrm{~A} / \mathrm{m}^{2}$.

Table 1. Chemical composition of the material used (mass\%)

\begin{tabular}{lccccccccc}
\hline Material & $\mathrm{C}$ & $\mathrm{Si}$ & $\mathrm{Mn}$ & $\mathrm{P}$ & $\mathrm{S}$ & $\mathrm{Cr}$ & $\mathrm{Ni}$ & $\mathrm{Mo}$ & $\mathrm{N}$ \\
\hline 316SI* & 0.005 & 1.38 & 1.35 & 0.014 & 0.009 & 17.32 & 13.59 & 2.34 & 0.001 \\
\hline
\end{tabular}

* The modified AISI $316 \mathrm{~L}$ stainless steel, where the code indicated is used only to refer the material with the given chemical composition.

\section{RESULTS}

Figure 1 shows the $\left(P_{\mathrm{h}}-P_{0}\right) / P_{0}$ vs. $N_{\mathrm{f}}$ data observed for the NL-tests at $300 \mathrm{~K}$ here or at $333 \mathrm{~K}[6]$, the TPtests at $333 \mathrm{~K}$ with $\Delta T$ below $10 \mathrm{~K} \mathrm{[6]} \mathrm{and} \mathrm{the} \mathrm{TP-}$ tests at $300 \mathrm{~K}$ with $\Delta T=70 \sim 130 \mathrm{~K}$, where TP with $\Delta T$ below $10 \mathrm{~K}$ brings about elongation of $N_{\mathrm{f}}$ but TP with increased $\Delta T$ of $70 \sim 130 \mathrm{~K}$ gives rise to shortening of $N_{\mathrm{f}}$. Figure 2 is a redrawing of Fig. 8 in [6], where the $\left(P_{\mathrm{h}}-P_{0}\right) P_{0}$ vs. $N_{\mathrm{f}}$ data observed for the pulse-PI-tests at $333 \mathrm{~K}$ are compared with the results for the TPtests at $333 \mathrm{~K}$ with $\Delta T$ below $10 \mathrm{~K}$. As mentioned in the section 1 , the in situ radiation damage at $333 \mathrm{~K}$ causes shortening of $N_{\mathrm{f}}$, especially in the low $\left(P_{\mathrm{h}^{-}}\right.$ $\left.P_{0}\right) / P_{0}$ range. Figure 3 shows the $\left(P_{\mathrm{h}}-P_{0}\right) / P_{0}$ vs. $N_{\mathrm{f}}$ data observed for the NL-tests at $403 \mathrm{~K}$ and the PItests at $403 \mathrm{~K}$, where a redrawing of the data of the NL-tests at $300 \mathrm{~K}$ or $333 \mathrm{~K}$ is also given. The $\left(P_{\mathrm{h}^{-}}\right.$ $\left.P_{0}\right) / P_{0}$ vs. $N_{\mathrm{f}}$ data observed for the NL-tests at $403 \mathrm{~K}$

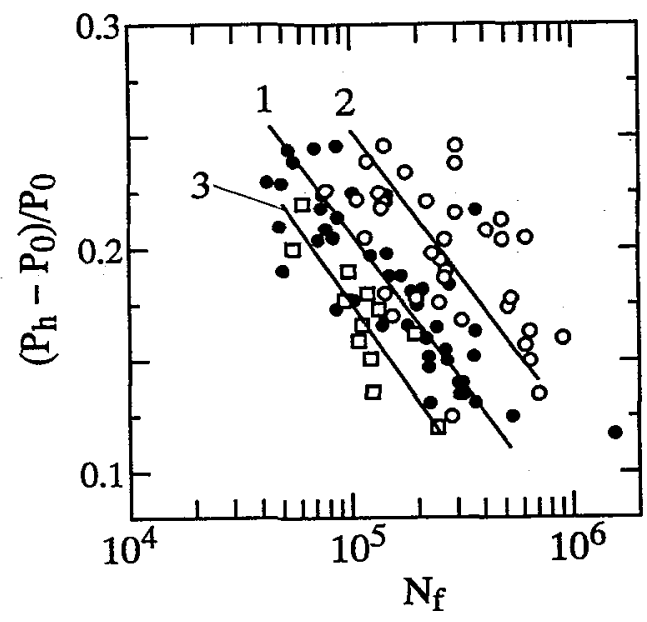

Figure 1. $\left(P_{\mathrm{h}}-P_{0}\right) / P_{0}$ vs. $N_{\mathrm{f}}$ observed for the fatigue tests at $300-330 \mathrm{~K}$ (see text)., $1=\mathrm{NL}$-tests; $0,2=\mathrm{TP}$ tests with $\Delta T$ below $10 \mathrm{~K} ; \square, 3=T$ P-tests with $\Delta T=70$ 130K. The lines 1 to 3 are tentatively fitted to the data. 
show good agreement with those observed for the NL-tests at $300 \mathrm{~K}$ or $333 \mathrm{~K}$. The outline of the effects of in situ radiation damage on $N_{\mathrm{f}}$ at $403 \mathrm{~K}$ is very similar to that of in situ radiation damage on $N_{\mathrm{f}}$ at $333 \mathrm{~K}$. The results of the scanning electron microscope (SEM) observation of the specimen surfaces will be mentioned in the section 4 .

\section{DISCUSSION}

A scatter in the present $\left(P_{\mathrm{h}}-P_{0}\right) / P_{0}$ vs. $N_{\mathrm{f}}$ data is relatively large due to the limited thickness of the present specimens, in order to allow the complete penetration of $20 \mathrm{MeV}$ protons. That is, the limited number of grains along the thickness, two or three here, are mainly responsible for the scatter in $N_{\mathrm{f}}$, presumably reflecting the crystallographic dependence of the dislocation behavior. However, the outline of the $\left(P_{\mathrm{h}}-P_{0}\right) / P_{0}$ vs. $N_{\mathrm{f}}$ data is expected to represent that of polycrystalline specimens. It is noted that the line 1 for the NL-tests shown in Fig. 1 or Fig. 3 falls on the extension from the $\varepsilon_{\mathrm{p}}$ vs. $N_{\mathrm{f}}$ data reported for the low cycle fatigue tests of the 316L stainless steel [7].

We now discuss the results of the various tests at $300 \mathrm{~K}$ or $333 \mathrm{~K}$. As mentioned in Fig. 3 , the $\left(P_{\mathrm{h}^{-}}\right.$ $\left.P_{0}\right) / P_{0}$ vs. $N_{\mathrm{f}}$ data for the NL-tests at $403 \mathrm{~K}$ show good agreement with those for the NL-tests at 300 $\mathrm{K}$ or $333 \mathrm{~K}$, being in agreement with that $N_{\mathrm{f}}$ of the

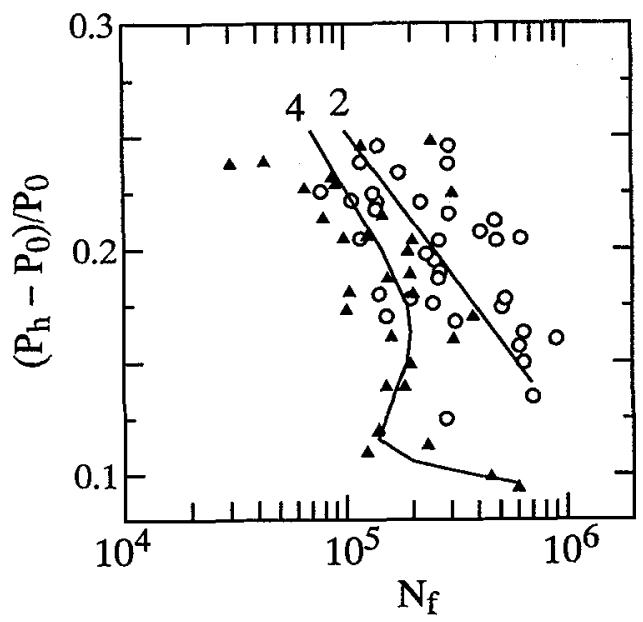

Figure 2. $\left(P_{\mathrm{h}}-P_{0}\right) / P_{0}$ vs. $N_{\mathrm{f}}$ observed for the tests at 333 $\mathrm{K}$. $O, 2=\mathrm{TP}$-tests with $\Delta T$ below $10 \mathrm{~K} ; \Delta, 4=$ pulse-PItests. The lines 2 and 4 are tentatively fitted to the data. See text.

solution-treated $316 \mathrm{~L}$ stainless steel is not sensitive to the test temperatures [7]. It is noted that the heart of the TP-tests is the abrupt change in the specimen temperatures, i.e., gradual changes in the specimen temperatures hardly modify $N_{\mathrm{f}}$. For the TP-tests at $333 \mathrm{~K}$ with $\Delta T$ below $10 \mathrm{~K}$ shown in Fig. 1 , since the fatigue hardening process for the isothermal tests at $333+10 \mathrm{~K}$ is practically the same to that at $333 \mathrm{~K}$, the elongation in $N_{\mathrm{f}}$ for the TP-tests should be due to dislocation rearrangements during TPs, suggesting an increase in the areal density of persistent slip bands (PSBs) because of a decrease in the plastic strain per PSB. In contrast, the results of the pulse-PI-tests at $333 \mathrm{~K}$ shown in Fig. 2 suggest that an introduction of obstacles to dislocation motions, irradiation induced defects here, gives rise to a decrease of PSBs, resulting in the shortening in $N_{\mathrm{f}}$. For the TP-tests at $300 \mathrm{~K}$ with $\Delta T=70 \sim 130 \mathrm{~K}$, one can expect both dislocation rearrangements and an introduction of obstacles, the fatigue induced precipitates here (see Fig.6 in [6]), during TPs, and the results of $N_{\mathrm{f}}$ suggest that the effect of the latter is predominant.

The SEM observation indicates that the above view is the case: In the present test conditions, the specimens failed through the transgranular mode and striations are observed on the fracture surface. On the surfaces of the specimens subjected to NL-tests at $300 \mathrm{~K}$ or $333 \mathrm{~K}$, PSBs are observed for about $20 \%$ of constituent grains and no visible slip bands for the remaining grains. Referring to the specimens subjected to the NL-tests at $300 \mathrm{~K}$ or $333 \mathrm{~K}$, the fraction of constituent grains which show PSBs is about twice for the specimens subjected to the TP-test at $333 \mathrm{~K}$ with $\Delta T$ below $10 \mathrm{~K}$, about one half for the specimens subjected to the pulse-PI-tests at $333 \mathrm{~K}$ and much smaller for the TP-tests at $300 \mathrm{~K}$ with $\Delta T=70$ $\sim 130 \mathrm{~K}$, respectively. That is, the close correlation between the PSBs and $N_{\mathrm{f}}$ evolutions is found.

For the tests at $403 \mathrm{~K}$, both enhanced dislocation motions and the fatigue induced precipitation are expected for the NL-tests. The $\left(P_{\mathrm{h}}-P_{0}\right) / P_{0}$ vs. $N_{\mathrm{f}}$ data for the NL-tests, however, indicate that the fatigue induced precipitation plays the minor role on the fatigue process during the NL-tests at $403 \mathrm{~K}$, predicting that for the PI-tests, irradiation induced lattice defects can serve as obstacles to dislocation motions and the probable irradiation dispersion of the fatigue induced precipitates [6] plays the minor role. The results of $N_{\mathrm{f}}$ found for the PI-tests at $403 \mathrm{~K}$ support this view. The SEM observation for the specimens subjected to the PI-tests at $403 \mathrm{~K}$ will be reported elsewhere after attenuation of radio activity of the specimens. 
The present results suggests that the dislocation interaction plays the major role on the high cycle fatigue properties of $316 \mathrm{SI}$. As a matter of fact, the work hardening exponent $n$ [8] estimated from the line 1 shown in Fig. 1 is as high as $n=1$ (see [6] for details). For the effects of in situ radiation damage on $N_{\mathrm{f}}, 316 \mathrm{SI}$ reveals shortening of $N_{\mathrm{f}}$ at $333 \mathrm{~K}$ or $403 \mathrm{~K}$. On the other hand, an opposite and an intermediate effects of in situ radiation damage on $N_{\mathrm{f}}$ are observed for various $316 \mathrm{~L}$ stainless steels: Elongation of $N_{\mathrm{f}}$ at $333 \mathrm{~K}$ is found for $316(\mathrm{ST}-1)$ in [4] in which the work hardening exponent $n$ is as low as about 0.2 and fatigue induced precipitates can be observed as black dots in TEM observation [5]. Shortening of $N_{\mathrm{f}}$ for the higher $\left(P_{\mathrm{h}}-P_{0}\right) / P_{0}$ range and elongation of $N_{\mathrm{f}}$ for the lower $\left(P_{\mathrm{h}}-P_{0}\right) / P_{0}$ range are observed for $316 \mathrm{~F}$ in [5] in which the work hardening exponent $n$ is about 0.33 and the fatigue induced precipitation is intermediate between $316(\mathrm{ST}-1)$ and $316 \mathrm{SI}$. That is, the systematic relationship between the effect of in situ radiation damage on $N_{\mathrm{f}}$ and the fatigue hardening process is found. To clarify this issue, the further work is now in progress.

\section{CONCLUSION}

The high-cycle fatigue tests of $316 \mathrm{SI}$ were carried out between 300 and $403 \mathrm{~K}$. The no loading tests indicate that the dislocation interaction governs the fatigue properties of $316 \mathrm{SI}$. The in situ irradiation tests and the in situ thermal-pulse tests indicate that dislocation rearrangements due to thermal-pulse give rise to an increase in the areal density of PSBs, resulting in elongation of the fatigue life $N_{\mathrm{f}}$, and an introduction of obstacles to dislocation motions, irradiation induced lattice defects or the fatigue induced precipitates, brings about a decrease in the areal density of PSBs, giving shortening of $N_{\mathrm{f}}$. In contrast, as reported in the previous work, for the 316L stainless steels in which the fatigue induced precipitation governs the high-cycle fatigue properties, an introduction of obstacles of dislocation motions gives rise to elongation of $N_{\mathrm{f}}$.

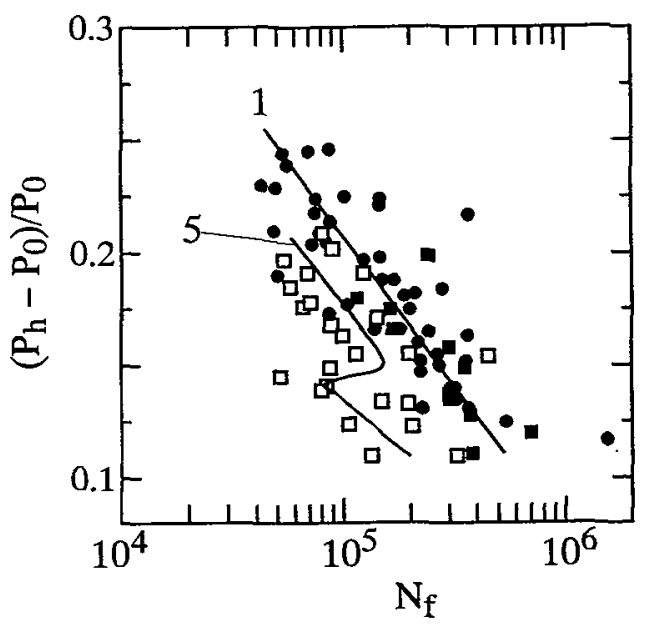

Figure 3. $\left(P_{\mathrm{h}}-P_{0}\right) / P_{0}$ vs. $N_{\mathrm{f}} \cdot \bullet, 1=\mathrm{NL}$-tests at $300-333 \mathrm{~K}$ (see text); $\square=\mathrm{NL}$-tests at $403 \mathrm{~K} ; \square, 5=$ PI-tests at $403 \mathrm{~K}$ The lines 1 and 5 are tentatively fitted to the data.

Acknowledgements

The authors are grateful to the staffs of the Tandem Accelerator Center of University of Tsukuba for their invaluable helps on the course of irradiation experiments. This work is partly supported by a Grant in Aid for Scientific Research from the Ministry of Education, Science and Culture of Japan.

\section{References}

[1] Jung P. and Ullmaier H., J. Nucl. Mater., 174(1990), 253.

[2] Grossbeck M.L., Ehrich K. and Wassilew C., J. Nucl. Mater., 174(1990), 264.

[3] Lindau R. and Moeslang A., J. Nucl. Mater., 179/181(1991), 753.

[4] Mizubayashi H., Okuda S., Nakagome K., Shibuki H. and Seki S., Mater. Trans. Jpn. Inst. Metals, 25(1992), 257

[5] Mizubayashi H., Fujita T., Yan S.-C. and Okuda S., Mater. Trans. Jpn. Inst. Metals, 32(1991), 539.

[6] Mizubayashi H., Ikemi K., Tanimoto H. and Okuda S., Mater. Trans. Jpn. Inst. Metals, 33(1992), 816.

[7] Furuya K., Nagata N. and Watanabe R., J. Nucl. Mater., 89(1980), 372.

[8] Marshall P., "Austenitic Stainless Steels; Microstructure and Mechanical Properties", (Elsevier Appl. Sci. Pub., London, 1984) p.175. 